Check for updates

The BMJ

Cite this as: BMJ 2021;372:n420 http://dx.doi.org/10.1136/bmi.n420 Published: 11 February 2021

\section{Covid-19: Healthcare staff must be given time to recuperate from pandemic, say leaders}

\section{Abi Rimmer}

The NHS must have a realistic and steady approach to resuming services disrupted by the pandemic that explicitly recognises the need for staff to recover, NHS leaders have said.

In a letter to the prime minister leaders from the NHS Confederation, which represents healthcare providers, warned, "The NHS cannot recover its services at the same rate of increase when staff are so exhausted."

The letter noted that there were over 5000 more patients with covid-19 in UK hospitals right now that at the peak of the first wave and that this was taking its toll on staff. The leaders called for sustained local mental health support for the NHS workforce beyond the end of March and for a long term, fully funded plan to increase staffing numbers.

The government must also set out clear expectations for the public on when routine procedures and other treatments would be fully back on line, they added.

"With a workforce on its knees and many of the pre-pandemic challenges still very much at play they need your government both to acknowledge the consequences of the immense pressure their workers have been under so far, and to be realistic and honest with the public about what the NHS can safely deliver moving forward," the letter said.

Layla McCay, director of policy at the NHS Confederation, said that while health leaders would continue to prioritise urgent care and patients with the greatest clinical need, the prime minister must "be upfront with the public about what the NHS can safely deliver in this next phase.”

"This includes setting clear expectations on activity, allocating resources where they are needed most, and moving away from upholding unrealistic standards that will be impossible to deliver in the short term," McCay said. "These do nothing but demoralise NHS staff and perpetuate the misleading view that the service is failing.”

At a Royal College of Anaesthetists online event on 9 February, England's national medical director, Stephen Powis, was asked how the NHS could reduce the backlog of treatment created by the pandemic and also meet the need for clinicians to rest and recuperate.

Powis said, "I'm well aware that some clinicians, such our surgical colleagues, are anxious because they have patients who they want to get on and treat. I'm equally sure that our anaesthetic colleagues and theatre staff are exhausted because of all the work they have been doing around intensive care. This is something that we have to solve and address collectively."

Ravi Mahajan, president of the Royal College of Anaesthetists, added, "It's about having compassion and understanding that people are tired.

"The solutions have to come from us being together and showing that commitment. It could be simple things like looking after each other, getting to know the early signs of mental and physical illness, taking breaks, allowing people to take annual leave which is due, and adjusting the pace of recovery so that people recover as well as the activity recovers-so that in the longer run we have a healthier and more refreshed workforce." 